\title{
RFID Tag Location Determination System in the Parking Area Using K-Nearest Neighbor Algorithm
} Ahmad Fali OKLILAS ${ }^{1}$, Elvatyara Rahmadiany PUTERI ${ }^{2}$, and SAMSURYADI ${ }^{3 *}$

\author{
${ }^{1,2}$ Department of Computer Engineering Faculty of Computer Science Universitas Sriwijaya, Palembang, Indonesia \\ ${ }^{3}$ Department of Informatic Engineering Faculty of Computer Science Universitas Sriwijaya Palembang, Indonesia \\ *Corresponding author: syamsuryadi@unsri.ac.id
}

\begin{abstract}
This research was conducted to determine the position of the target tag placed in a predetermined position in a parking area. The method applied in this location determination system is the K-Nearest Neighbor algorithm method. There are two scenarios in this research, that are where the target tag is placed at two predetermined coordinate positions. This test uses 15 reference tags that are placed around two target tags with predetermined coordinate positions. So, after 10 tests, the prediction coordinates will be obtained in each data collection, which can then be used to find the average error rate of the two scenarios so that the scenario can be obtained which is more effective to be used in this research. From the two scenarios used, it is known that the error value of the first scenario is $7,0474 \mathrm{~cm}$, while the error value of the second scenario is $7,6773 \mathrm{~cm}$. From the results of the errors in the two scenarios of this experiment, it is known that the first scenario is much better used when taking the initial data or searching for the RSSI data, so that the results obtained are even better. In addition to manual calculations, calculations using programs with the Python programming language can also be done in order to produce more accurate predictive coordinates and error values.
\end{abstract}

Keywords: Radio Frequency Identification (RFID), K-NN, RFID tag

\section{INTRODUCTION}

RFID is a system that makes it easy to identify objects without direct contact with them. Another advantage of RFID compared to barcodes is that it does not need to be perpendicular between the object and the reader. To identify the exact location of an object, to know the correct position, then we need a method. The method used in this paper is the K-Nearest Neighbor algorithm or KNN method. This K-NN can precisely determine the location of an object so that if a vehicle is parked at a location, it will be known exactly where the position of the vehicle is. So far, the parking system only counts the number of vehicles entering and leaving and the length of time. In this paper, we will add how to position the vehicle also know the location of the parking lot, so that it can be seen in which parking slots are still empty and can know the location of the vehicle sought by the user. And also can maintain vehicle safety because if the position changes later it can be seen where the vehicle moved. K$\mathrm{NN}$ is used because this method can precisely find out the location of an object by referring to the previous reference tag because it is based on the nearest reference point or nearest neighbor.

A system is needed to find out the physical location of an object or human to optimize user experience and also solve logistical and security problems. Radio Frequency Identification (RFID) itself is a wireless technology that uses radio waves or frequency to use it to track, or determine the location of an object and also an automatic process. RFID technology itself can provide us with ease in knowing the physical location of an object or human [1].

RFID technology and K-Nearest Neighbor are used in this research because it is expected to provide efficient results.
RFID technology and K-Nearest Neighbor algorithm are also used because this technology and method provides identification and location determination at low cost because it has a small component size and also using low power consumption [1].

\section{LITERATURE STUDY}

\section{Location Determination System and Data Identification}

Current technology can be used to track the position of an object and identify it indoor and also outdoor, and there is also technology to track an object in close proximity, one example is finding a parking space for vehicles [6]. Here is a technology that can track and identify an object: 1 . GPS (Global Positioning System)[7]; 2. NFC (Near Field Communication)[8]; 3. RFID (Radio Frequency Identification).

\section{RFID (Radio Frequency Identification)}

RFID technology can be interpreted as a technology that allows data retrieval using a device called a tag, so that we do not need direct contact with a wireless transmitter (reader) to identify an object[10].

Based on resources for communication, RFID tags are divided into two types, which are active tags and passive tags. An active tag is an RFID tag that has its own energy and does not require a reader to make readings on a data. Meanwhile, passive tags are RFID tags that use electromagnetic energy received from a reader, which will then be used alone to reply to the reader. If we can 
implement the RFID technology properly, then the technology can provide us with so many advantages compared to conventional technology such as bar code technology that we often use before [11].

\section{K-Nearest Neighbor Algorithm(KNN)}

K-Nearest Neighbor (KNN) algorithm is a clarification method that groups a new data based on a new data distance to the nearest neighboring data [4]. The benefits of using this algorithm are this algorithm is resistant to interference such as noise, and data retrieval can also be done quickly and simply, and this algorithm also really good to use when we faces large amounts of data [12]. In this algorithm the parameters used are RSSI or the signal received from the target tag that wants to find its position (RSSI target) and RSSI from the reference tag as a reference tag $(\mathrm{Ri})$ and uses physical position in the form of coordinates of all reference tags (xi, yi) for estimate the position of the target tag (xe, ye)[5].

In the calculation of K Nearest Neighbor, it is necessary to find the Euclidian distance. Euclidian Distance (Ei) here is the distance between each reference tag and target tag in the RSSI value. This Euclidian distance (Ei) can be searched using equation (1) below:

$\mathrm{E}_{\mathrm{i}}=\left|\mathrm{RSSI}_{\text {target }}-\mathrm{R}_{\mathrm{i}}\right|$

In the calculation using K Nearest Neighbor also known as the weight value factor (Wi) which functions to make a reference tag that has an euclidian distance (Ei) closer than other reference tags will have a greater weight value. Equation Wi can be seen in equation (2) below:

$\mathrm{W}_{\mathrm{i}}=\frac{\frac{1}{E_{i}{ }^{2}}}{\sum_{j=1}^{k} \frac{1}{E_{j}{ }^{2}}}$

To find the approximate coordinate position $(\mathrm{x}, \mathrm{y})$ of the target tag, the coordinates position $(\mathrm{x}, \mathrm{y})$ of each reference tag must be known first. The approximate position of the target tag coordinates can then be searched using equation (3) below:

$\left(\mathrm{x}_{\mathrm{e}}, \mathrm{y}_{\mathrm{e}}\right)=\sum_{i=1}^{k} W_{i}\left(x_{i}, y_{i}\right)$

After all calculation processes using k Nearest Neighbors have been carried out and the estimated coordinate position has been obtained, then the search for the average value of the error (error) from the position can be done. Finding the average value of this error can be found using equation (4) below:

error $=\sqrt{\left(x-x_{e}\right)^{2}+\left(y-y_{e}\right)^{2}}$

\section{METHODOLOGY}

\section{Parameter of Research}

The design of this study uses a room that has dimensions of $3 \times 3$ meters, with two parking slots that have an area of $2 \times 1$ meters each. The coordinates used are per $10 \mathrm{~cm}$. The actual coordinates are predetermined to facilitate the search for reference coordinates. The following image below is a design of the test location.

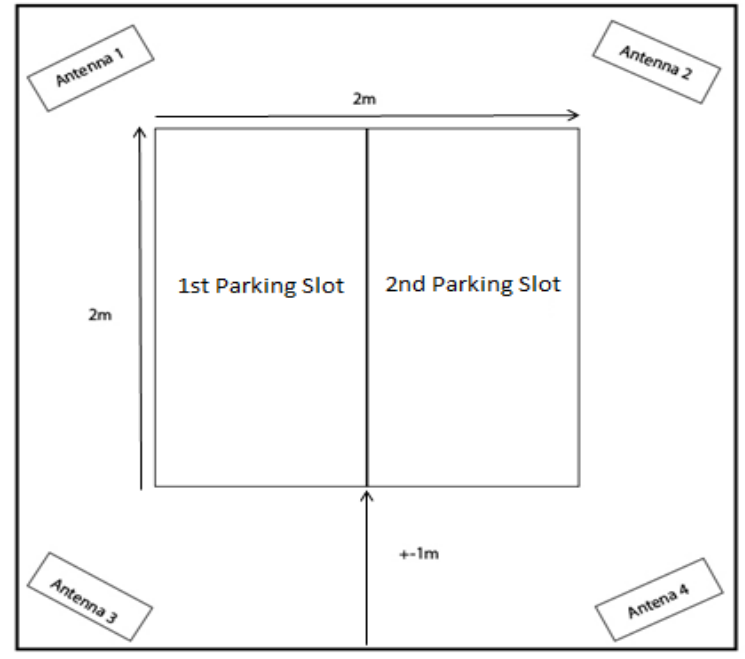

Figure 1. Location of test design

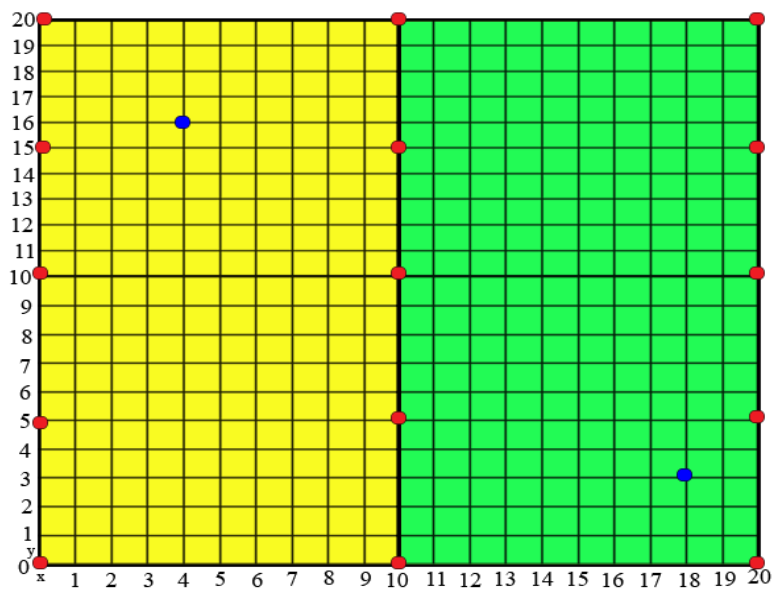

Figure 2. Tag positioning design

In this study, the reference tags used amounted to 15 pieces, which are placed in a position $6 \times 6$ around the two parking slots that have been provided and the main tags or target tags used amounted to 2 pieces. The red dot in figure 2 is the place where the reference tag is being placed, while the blue dot is the place where the target tag is being placed.

\section{Algorithm Steps}

In the algorithm step, the first thing to do is to find the RSSI value using a pre-configured RFID reader, which will be used as a basis for finding the Euclidean value of the target tag and reference tag, which will then be used to find the weight factor value which is then can produce predictive coordinates and error values. To find the Euclidean value, weight factor value and the predictive coordinates, we are using K-Nearest Neighbor algorithm.

\section{Tag and Reader Positioning}

In this study there was only one reader used, the antennas used amounted to 4, while the reference tags used amounted to 15 pieces with a target tag of 2 pieces. The 


\section{RESULTS AND DISCUSSION}

position of the reader is within the reach of the antenna cable. While the four antennas are placed in the corner of the test location around the location of two predetermined parking slots.

This method uses Signal Strength or RSSI as its parameters. The position of the antenna is placed approximately 1 meter from the location of the two parking slots. Placing this antenna also affects the results of the error later, because if the position of the antenna is shifted just a little then the RSSI value will most likely also change.

The position of the antenna that surrounds the two parking slots must be adjusted so that all reference tags and target tags can be read by the reader.

\section{RSSI Values Testing}

The first test is to look for the RSSI (Received Signal Strength Indicator) value for each tag. Following is the RSSI value table from the reference tag and target tag. The two tables below are RSSI values of 15 Reference Tags and 2 Target Tags used in testing.

Table 1. RSSI values of reference tags and target tags from first scenario

\begin{tabular}{|c|c|c|c|c|c|c|c|c|c|c|c|}
\hline No. & $T 1$ & $R 1$ & $R 2$ & $R 3$ & $R 4$ & $R 5$ & $R 6$ & $R 7$ & $R 8$ & R9 & $R 10$ \\
\hline 1. & 1585 & 965 & 967 & 1004 & 1043 & 809 & 801 & 785 & 1089 & 1026 & 1023 \\
\hline 2. & 1552 & 909 & 912 & 1131 & 1026 & 764 & 760 & 867 & 1087 & 1243 & 1240 \\
\hline 3. & 1717 & 796 & 801 & 1020 & 873 & 672 & 665 & 926 & 1149 & 1027 & 1023 \\
\hline 4. & 1556 & 852 & 855 & 1096 & 896 & 753 & 750 & 875 & 1268 & 1239 & 1230 \\
\hline 5. & 1773 & 788 & 790 & 1011 & 1006 & 758 & 752 & 835 & 1205 & 909 & 906 \\
\hline 6. & 1611 & 713 & 715 & 1106 & 999 & 683 & 680 & 899 & 1178 & 980 & 975 \\
\hline 7. & 1618 & 883 & 888 & 983 & 952 & 891 & 887 & 808 & 1083 & 986 & 983 \\
\hline 8. & 1653 & 884 & 897 & 1207 & 971 & 765 & 761 & 889 & 1051 & 898 & 895 \\
\hline 9. & 1609 & 785 & 787 & 1216 & 1058 & 812 & 809 & 879 & 1096 & 1029 & 1026 \\
\hline 10. & 1517 & 718 & 723 & 1049 & 919 & 941 & 937 & 795 & 1172 & 859 & 856 \\
\hline
\end{tabular}

Table 2. RSSI values of reference tags and target tags from second scenario

\begin{tabular}{l|lllllllllll}
\hline No. & T2 & $\boldsymbol{R 6}$ & $\boldsymbol{R} 7$ & $\boldsymbol{R} 8$ & $\boldsymbol{R} 9$ & $\boldsymbol{R 1 0}$ & $\boldsymbol{R 1 1}$ & $\boldsymbol{R 1 2}$ & $\boldsymbol{R} 13$ & $\boldsymbol{R} 14$ & $\boldsymbol{R} 15$ \\
\hline 1. & 1655 & 801 & 785 & 1089 & 1026 & 1023 & 939 & 931 & 1083 & 1080 & 1078 \\
2. & 1622 & 760 & 867 & 1087 & 1243 & 1240 & 1080 & 815 & 901 & 900 & 898 \\
3. & 1787 & 665 & 926 & 1149 & 1027 & 1023 & 965 & 833 & 785 & 781 & 779 \\
4. & 1626 & 750 & 875 & 1268 & 1239 & 1230 & 1128 & 1008 & 952 & 950 & 946 \\
5. & 1843 & 752 & 835 & 1205 & 909 & 906 & 958 & 862 & 847 & 846 & 842 \\
6. & 1681 & 680 & 899 & 1178 & 980 & 975 & 921 & 809 & 915 & 911 & 908 \\
7. & 1688 & 887 & 808 & 1083 & 986 & 983 & 1136 & 867 & 982 & 980 & 978 \\
8. & 1729 & 761 & 889 & 1051 & 898 & 895 & 1029 & 853 & 1016 & 1011 & 1008 \\
9. & 1679 & 809 & 879 & 1096 & 1029 & 1026 & 1091 & 922 & 878 & 873 & 870 \\
10. & 1577 & 937 & 795 & 1172 & 859 & 856 & 1040 & 768 & 920 & 919 & 917 \\
\hline
\end{tabular}




\section{Euclidean Value and Weight Value (W)}

and the reference tag in $\mathrm{dBm}$ for the first scenario. The first scenario is the scenario in the first parking slote where the first target tag is placed with 10 reference tags surrounding it. After obtaining the RSSI value from the target tag and reference tag, then the calculation will be performed to find the Euclidian Distance (Ej) and weight

Euclidean value is the result of the difference between the target tag and the reference tag using equation (1). The following tables below are Euclidian (Ej) values.

Table 3. Euclidean and weight values of first target tag and first reference tag from first scenario

\begin{tabular}{l|ll}
\hline No & $\boldsymbol{E}_{\boldsymbol{I}}$ & $\boldsymbol{W}_{\boldsymbol{I}}$ \\
\hline 1. & 620 & 0.0968 \\
2. & 643 & 0.0540 \\
3. & 921 & 0.0713 \\
4. & 704 & 0.0423 \\
5. & 985 & 0.0720 \\
6. & 898 & 0.0524 \\
7. & 735 & 0.0833 \\
8. & 769 & 0.0801 \\
9. & 824 & 0.0537 \\
10. & 799 & 0.0499 \\
\hline
\end{tabular}

The Euclidian value in the table above is the Euclidian value for the first scenario generated from the first RSSI scenario in table 1. To get the Euclidean value in the second scenario, use the same method used to get the Euclidean value for the first scenario. After getting the Euclidean value, then the weight factor value can be searched using the equation (2).

\section{Coordinate and Error}

After the weight factor has been obtained, the next step is to find the approximate coordinates of the target tag position based on the weight factor value and the reference tag coordinates. In this paper to find coordinates and errors using equations 3 and 4 . Here is a table of estimated coordinate values and error values for each $\mathrm{k}$ in the study: 
Table 4. Approximate coordinates and error values of both scenarios

\begin{tabular}{|c|c|c|c|c|c|c|}
\hline No & $x_{e}$ firts & $y_{e}$ first & error first & $x_{e}$ first & $\begin{array}{l}y_{e} \\
\text { second }\end{array}$ & $\begin{array}{l}\text { error } \\
\text { second }\end{array}$ \\
\hline 1 & 5,0695 & 8,9184 & $7,1619 \mathrm{~cm}$ & 14,3888 & 9,9478 & $7,8302 \mathrm{~cm}$ \\
\hline 2 & 6,4914 & 7,0838 & $9,2577 \mathrm{~cm}$ & 11,2341 & 6,9722 & $7,8458 \mathrm{~cm}$ \\
\hline 3 & 5,9165 & 9,0434 & $7,2157 \mathrm{~cm}$ & 12,8209 & 8,7778 & $7,7593 \mathrm{~cm}$ \\
\hline 4 & 7,3553 & 7,4645 & $9,1714 \mathrm{~cm}$ & 11,8385 & 7,4121 & $7,5783 \mathrm{~cm}$ \\
\hline 5 & 5,4912 & 9,8603 & $6,3182 \mathrm{~cm}$ & 13,5219 & 9,4323 & $7,8376 \mathrm{~cm}$ \\
\hline 6 & 5,6768 & 9,5969 & $6,6191 \mathrm{~cm}$ & 13,2581 & 9,4236 & $7,9842 \mathrm{~cm}$ \\
\hline 7 & 5,3416 & 9,6093 & $6,5300 \mathrm{~cm}$ & 14,2893 & 9,0847 & $7,1269 \mathrm{~cm}$ \\
\hline 8 & 4,3695 & 9,6557 & $6,3551 \mathrm{~cm}$ & 14,6274 & 9,8895 & $7,6707 \mathrm{~cm}$ \\
\hline 9 & 4,7920 & 9,6651 & $6,3842 \mathrm{~cm}$ & 13,4940 & 8,5388 & $7,1402 \mathrm{~cm}$ \\
\hline 10 & 5,6942 & 10,8087 & $5,4607 \mathrm{~cm}$ & 13,8509 & 9,8398 & $7,9999 \mathrm{~cm}$ \\
\hline \multicolumn{3}{|c|}{ Average error } & $7,0474 \mathrm{~cm}$ & Average erro & & $7,6773 \mathrm{~cm}$ \\
\hline
\end{tabular}

From the table above, it is known that the average of all errors obtained is $7.0474 \mathrm{~cm}$. As for the second scenario, the average of all errors obtained is $7.6773 \mathrm{~cm}$. From the results of errors generated in the two scenarios of this experiment, it is also known that the error value obtained in the first scenario has a slightly lower error rate than the second scenario with a difference of 0.6299 centimeters. The error value generated here can be caused by several factors, such as the placement of an inappropriate RFID antenna and the location of the data retrieval that has a lot of interference. From all of the results, we found that KNearest Neighbor algorithm can be used as a good method in finding the position of an object in this research because it has some benefits like does not produce an error trade that is too high, easy to use when it comes to using large amount of data, and we can also doing retrieval data simpler and quicker.

\section{SUMMARY}

Based on the test results obtained, testing the second scenario or by using the second target tag on coordinates (18.3) or the second scenario has a slightly greater error rate when compared to testing using the first scenario or the first target tag on coordinates (4.16). The smallest average error obtained in the first scenario test is 7.0474 and has a difference of 0.6299 centimeters with the average error obtained in the second scenario test, which are 7.6773. So, it can be concluded that the first scenario is the best scenario in this research. The error value that obtained in this research can be caused by several things, including human error because the calculations are done manually. Interference between tags and also the improper placement of antennas can also interference the inquiry process and response of the RFID. However, from the entire research, we can also conclude that RFID and K-
Nearest Neighbor algorithm can be used as a method in finding the position of an object.

\section{REFERENCES}

[1] Everton Luis Berz, Deivid Antunes Tesch, Fabiano Passuelo Hessel, "RFID Indoor Lozalization Based on Support Vector Regression and K-Means", PUCRS University. 2015.

[2] L. Ni, D. Zhang, and M. Souryal, "RFIDbased localization and tracking technologies," IEEE Wireless Communications, vol. 18, no. 2, pp. 45-51, Apr. 2011.

[3] M. Ismail, "Rancang Bangun Pengukur Rssi (Receive Signal Strength Indicator) Berbasis Aplikasi Android Menggunakan App Inventor," pp. 25-30, 2018.

[4] Rohman Abdul, "MODEL ALGORITMA KNEAREST NEIGHBOR (K-NN) UNTUK PREDIKSI KELULUSAN MAHASISWA", Universitas Pandanaran, Semarang. 2015.

[5] A.F. Oklilas and Muhammad Zikrillah, 2017, "Pengaruh Penempatan Antena di Ruang Kelas pada Sistem Presensi Mahasiswa Berbasis RFID Menggunakan Algoritma K-Nearest Neighbor", Universitas Sriwijaya. 
[6] A.F. Oklilas and M. Wulandari, 2017, "Penerapan Metode LANDMARC Menggunakan Manhattan Distance untuk Penentuan Lokasi RFID Tag pada Area Parkir Kendaraan Roda Dua”, Universitas Sriwijaya, vol 3, no.1, pp. 139-143.

[7] Setiawan Eko Budi, Bobi Kurniawan, “ Perancangan Sistem Absensi Kehadiran Perkuliahan dengan Menggunakan Radio Frequency Identification (RFID)", Universitas Komputer Indonesia, 2015.

[9] J. S. Choi, H. Lee, R. Elmasri, and D. W. Engels, "Localization Systems using Passive UHF RFID," Int. Jt. Conf. INC, IMS IDC, pp. 1727-1732, 2009.

[10] Zheng Jiali, Tuanfa Qin, Jieming Wu and Li Wau, "RFID Indoor Localization Based on Relational Aggregation”, Chang Mai, Thailand, pp.41-44, 2016.

[11] A. Sultana and A. Sobhan, "RFID in Healthcare Systems : Applications and Implications," Int. Conf. Electron. Comput. Commun., vol. 1, no. June 2008, p. 4, 2008.

[12] T. Karygiannis, B. Eydt, G. Barber, L. Bunn, and T. Phillips, "Guidelines for securing radio frequency identification (RFID) systems-Recommendations of the," Natl. Inst. Stand. ..., 2007.

[13] Siti Mutrofin, Abidatul Izzah, Arrie Kurniawardhani, Mukhamad Masrur, 2014, "Optimasi Teknik Klasifikasi Modified K-Nearest Neighbor Menggunakan Algoritma Genetika”, Universitas Pesantren Tinggi Darul 'Ulum. 